\title{
Ilkka Hanski and small mammals: from shrew metapopulations to vole and lemming cycles
}

\author{
Heikki Henttonen ${ }^{1}$, Olivier Gilg ${ }^{2,3}$, Rolf A. Ims ${ }^{4}$, Erkki Korpimäki ${ }^{5}$ \& \\ Nigel G. Yoccoz ${ }^{4}$
}

1) Natural Resources Institute Finland (Luke), P.O. Box 2, Fl-0790 Helsinki, Finland

2) Groupe de Recherche en Ecologie Arctique, F-21440 Francheville, France

3) Université de Bourgogne Franche Comté, Equipe Ecologie-Evolution, UMR 6282 Biogéosciences, F-21000 Dijon, France

4) Department of Arctic and Marine Biology, The Arctic University of Norway, N-9047 Tromsø, Norway

5) Section of Ecology, Department Biology, Fl-20014 University of Turku, Finland

Received 20 Feb. 2017, final version received 5 Apr. 2017, accepted 5 Apr. 2017

Henttonen, H., Gilg, O., Ims, R. A., Korpimäki, E. \& Yoccoz, N. G. 2017: Ilkka Hanski and small mammals: from shrew metapopulations to vole and lemming cycles. - Ann. Zool. Fennici 54: 153-162.

Ilkka Hanski may be best known for his work on insect and metapopulation dynamics, but he also contributed significantly to small mammal research. In the early 1980s he became interested in shrew dynamics, energetics, and of course, shrew metapopulations. He aimed at understanding the population biological consequences of body size in different shrew species. Feeding habits and environmental stochasticity affect shrew species in profoundly different ways: due to their short survival time small species have high extinction rates but their dispersal and colonization capacity is high which enables them to survive as metapopulations. After Hansson and Henttonen reported the Fennoscandian gradients in vole dynamics in the mid-1980s, Hanski became interested in vole and lemming cycles. The first models on this were published with Henttonen and Hansson in 1991 where the roles of specialist and generalist predators were assessed. Later, the models were further developed with Korpimäki and Turchin, with model parametrization from Microtus biology and including both specialist mammalian predators as well as avian predators. A special case was the model with Henttonen on competing vole species with a shared predator (apparent competition), which was related to the long-term fading out of vole cycles in Finnish Lapland in the mid-1980s (which though returned in the early 2010s). Later Hanski became interested in the work of Sittler and Gilg in Greenland. Together they modelled the very simple vertebrate community and showed how stoats played a pivotal role in generating a population cycle in the collared lemming. In addition to these specific works, Hanski was leading collaborator in several reviews on small rodent cycles and predation. He intended to return to shrew biology, but that never realized. Hanski was a fearless field biologist, but he always aimed at understanding natural phenomena at more general, theoretical level. 


\section{Shrew dynamics and metapopulations}

Ilkka Hanski started his work on small mammals at the beginning of the 1980s. His first interest was in shrews (Sorex). He had learned to know Asko Kaikusalo, a keen naturalist though without academic background, who had been working with small mammals since the late 1950s, e.g. as a field assistant of prof. Olavi Kalela, the leading vole and lemmings scientist in Finland during the 1950s and 1960s. In addition to the official vole and lemming monitoring at the Kilpisjärvi Biological Station, Kaikusalo carried out his own regular trappings. Kaikusalo's shrew material covered two decades, and Hanski realized that no real time series analyses on shrew dynamics existed in contrast to that on vole dynamics. Their joint paper (Kaikusalo \& Hanski 1985) was published in the congress proceedings three years after the 2nd Theriological Congress where the material was presented.

The article shows characteristically Hanski's analytic approach. Shrew dynamics are compared with those of sympatric voles species, butterfly abundance index (remember, shrews are insectivores), and vole and shrew autocorrelation analyses are run. Density dependencies in summer and winter were estimated separately, taking into consideration seasonality which was not too common in those days. There were some indications that shrew peaks occurred a year after the vole decline, when voles were still at low densities. Also, some of the shrew peaks occurred during good butterfly summers, perhaps related to summer climate and feeding conditions at the latitude $69^{\circ} \mathrm{N}$. Density dependence was clear in summer, the lower the spring density, the better the summer growth rate. On the other hand, there was no density dependence in winter. This approach of autocorrelation patterns and density dependencies was later expanded to all long-term time series of the common shrew (Sorex araneus) in Finland by Henttonen et al. (1989) and published in a special issue of Annales Zoologici Fennici entitled "Population biology of Eurasian shrews" edited by Hanski and Pankakoski (1989).

This special issue included 14 articles, covering shrew population dynamics, genetics, para- sites, foraging behaviour and morphometrics. In one of his own articles, Hanski (1989) compared the body size distributions of Eurasian and American shrew species and showed that distributions were quite similar from small to large species. Hanski also compared the body size distributions and abundances of shrew species in western and eastern Eurasia. When an abundant species was missing from one region, the "neighbouring" species seemed to undergo character displacement to partly fill the empty body size niche.

In the 1980s, Hanski collaborated with Russian shrew biologists and the special shrew issue included 3 articles from various parts of Siberia, covering long-term dynamics of multi-species shrew communities (Sheftel 1989) and intraspecific interactions in Sorex araneus (Moraleva 1989) in central Siberia, and population ecology of shrews in northeastern Siberia (Dokuchaev 1989). Hanski felt that it was important to introduce, obviously for the first time, these longterm Russian studies to western readers. Hanski himself visited some of the Siberian study sites.

To understand the population biological consequences of body size in Sorex shrews, Hanski and his collaborators studied the differences between small and large species from different angles. In Finland, there are 5 species of Sorex, from the smallest $S$. minutissimus with juvenile weight of $2 \mathrm{~g}$ to $S$. isodon with juvenile weight of $10 \mathrm{~g}$. Hanski's team analysed the metabolic consequences of body size, behavioural responses to variation in food availability, population dynamics and body size including dispersal, colonization and extinction, community structure including size distributions of coexisting species, habitat selection and competition. A comprehensive summary of the work is given in Hanski (1994). Table 1 presents slightly modified description how these various processes in relation to body size take place at the level of local populations, metapopulations, and species over evolutionary times scales.

Per-capita food requirements of small species are only about half that of the large species. However, the starvation time of the largest species is twice as long as that of the small species. This reflects the difference of mass-specific metabolic rate of smallest and largest species. With 
respect to handling time of prey, small species do well with both small and large prey items while large species do better with large prey items. Size-dependent starvation times have an effect on the survival of species when food availability is scarce, and therefore stochastic events may have greater impact on small species. It seems that small species are good colonizers. On the other hand, the minimum island/patch size for survival is clearly greater for small than large species. Extinction rate increases with decreasing body size, obviously partly due to shorter starvation time in small species. The impact of environment stochasticity is probably greater on small than large species and in poor rather than productive habitats.

Per-capita food requirements of large species are greater than those of small ones, hence large species may not survive in poor habitats. Empirical evidence supports the idea that small species dominate in poor habitats while large species in productive environments. It can also be a question of distribution of different types of food items in different habitats, even though interspecific competition among shrew species is well-documented.

Through his shrew studies Hanski also became interested in the role of insectivorous shrews as regulators of pine sawfly dynamics (Hanski 1987a, Hanski \& Parviainen 1987). It is known that sometimes predation by small mammals on sawfly cocoons can be considerable. Based on the finding that shrew densities are usually low in dry, unproductive habitats, where sawfly outbreaks often start, Hanski suggested that there was support for the hypothesis that shrew may indeed regulate some insect populations.

\section{Modelling vole and lemming dynamics}

The tradition of monitoring and studying vole cycles in Finland is long and fruitful, and therefore it is no wonder that also Hanski was caught by this passion. Debates on the causes of vole cycles (extrinsic or intrinsic) had been intense between the 1950s and the 1980s; even the expression "vole wars" has sometimes been used. From the modern perspective, the debates may look a bit strange: why such a fight? It must, however, be recognized that in those old days there were much fewer data available, particularly long-term data, and also it seemed to be a common thinking that all vole populations are cyclic, and logically then, there must be one common explanation, and it was worth debating.

Hansson and Henttonen (1985a, 1985b, 1988) and Henttonen et al. (1985) published a series of analyses of geographic patterns in vole cycles, especially geographic trends and gradients within species, and showed that dynamics are clearly related to climate and environmental conditions, "biome characteristics", that define the community structure and diversity

Table. 1. Impact of body size on the metapopulation dynamics of small shrew species. Modified from Hanski (1994: table 3).

Stability of local populations is decreased by ...

Stability of metapopulations is increased by ...

Stability of species over evolutionary time is increased by ... small body size $\rightarrow$ low interference competitive ability $\rightarrow$ low density in productive habitats with superior competitors abundant $\rightarrow$ high risk of extinction small body size and high metabolic rate $\rightarrow$ short starvation time $\rightarrow$ high risk of extinction of local populations due to environmental stochasticity

small body size $\rightarrow$ small per capita food requirements $\rightarrow$ local populations also in poor habitats good colonization ability $\rightarrow$ high colonization rate unstable local dynamics $\rightarrow$ low rate of speciation stable metapopulations dynamics $\rightarrow$ low rate of species extinction 
of ecological guilds. This diversity affects density dependencies, i.e. whether there is delayed density-dependence or not, and hence whether there are cycles or not. The main idea is that in the north high-amplitude population cycles are generated within a vertebrate community dominated by voles and their specialist predators, while in the south stability is promoted by the increased diversity of the prey and predator guilds. Empirical data on focal vertebrate community from southern Fennoscandia were presented by Erlinge et al. (1983), while equivalent data from the north and geographic comparisons analyses were lacking. Hansson and Henttonen (1985a) showed that in Fennoscandia an environmental gradient (seasonality, snow cover and productivity) underlies a corresponding gradient in vole dynamics and the vertebrate community diversity. They also proposed that the similar dynamic differences in vole populations between larger geographic areas in Eurasia and North America can be related to the same community patterns and environmental factors. So, this was the scene which Hanski entered in the mid-1980s.

Interactions between predators and preys attracted modellers right from the beginning of theoretical ecology, starting with the independent works by Lotka (1925) and Volterra (1926). Volterra in particular developed his model to analyse relationships between predatory fish and their preys. This simple linear model has periodic solutions (i.e., generates population cycles) and predator-prey interactions were suggested early (e.g. Lack 1954) as one explanation for population cycles in small mammals (voles, lemmings) and hares. General work on predatorprey interactions was further expanded in the 1960s, with some earlier contributions by in particular Leslie (1948), to include different functional responses of predators (e.g. Rosenzweig \& MacArthur 1963, May 1972, 1973, Andersson \& Erlinge 1977).

These models could not account, however, for some striking features in the small rodent cycles in Fennoscandia, unravelled in the 1980s by Hansson and Henttonen (1985a, 1988): (1) the large-scale geographical patterns in cycle period and amplitude, (2) the importance of seasonality, in particular through the role played by snow cover, and (3) the community composition and dynamics, both in terms of the predators and the preys. These features obviously intrigued Hanski to the extent that he wrote a commentary in Trends in Ecology \& Evolution (Hanski 1987b), which was his first paper about these phenomena. During the next decade or so, Hanski developed a succession of models (Fig. 1) that expanded the Leslie model used by May (1973), to address how interactions between rodents and predators in different ecological contexts could give rise to different population dynamics. Typically, Hanski's models stroke the balance between model complexity and the limitations imposed by the lack of detailed empirical knowledge, particularly on the predators.

The first modelling study (Hanski et al. 1991) aimed at explaining why small mammals showed large periodic (with a 4-5-year period) multiannual fluctuations in the north of Fennoscandia, whereas fluctuations were either with a short period (3 years) or mostly seasonal and non-periodic in the south. Leslie's model had a functional response typical of a specialist predator (Type II), and Hanski et al. (1991) added a generalist predation component (Type III), and studied how varying the relative importance of specialist $v s$. generalist predation could affect the cycle period and amplitude. An increasing generalist predation from north to south could explain the observed geographical gradient with shorter and more dampened cycles in south.

Up to the 1990s, predator-prey models were either continuous (e.g. Lotka-Volterra, May) or discrete (e.g. Leslie), but none included a seasonal component. Seasons (simplified to "summer" and "winter"), however, affect greatly preys and predators: small rodents (except lemmings) and predators mostly reproduce in the summer season. This was tackled for the first time by Hanski et al. (1993), by assuming different model components in summer and winter, and adding a threshold for the reproduction of predators (Fig. 1).

Hanski et al. (1993) used two mutually supportive approaches to study the interaction between Microtus voles and least weasels. In Fennoscandia, population cycles in Microtus voles are of high-amplitude with a period of 3-4 years, and least weasels are the predators 
Fig. 1. A visualisation of the predator-prey models developed by Ilkka Hanski to understand different facets of the small mammals' cyclic fluctuations. The core was the model of Leslie-May for specialist predation, to which was added (1) generalist predation), (2) seasonality, (3) competition between preys, and (4) stochasticity.

\section{Seasonality}

Two seasons: summer and winter Rodents: different $r$ and $K$ values for summer and winter Predators (Mustelids): rodent threshold density determines reproduction (growth) or decline

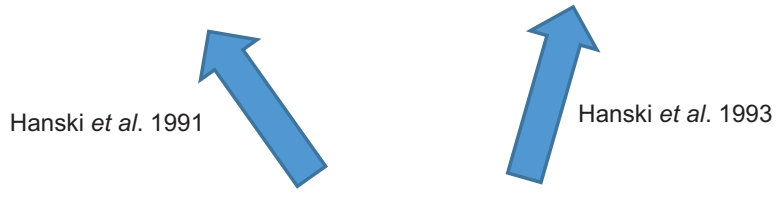

$\mathrm{N}$ : rodents

$\mathrm{P}$ : predators

$$
\frac{d N}{d t}=r N\left(1-\frac{N}{K}\right)-c \frac{P N}{N+D} \quad \text { Type II functional response }
$$
$d P=s P\left(1-\frac{P}{q N}\right) \quad$ Leslie 1948 May 1973

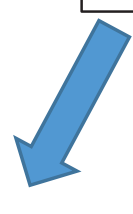

Two prey-predator

$$
\begin{aligned}
& \frac{d N_{1}}{d t}=r_{1} N_{1}\left(1-\frac{N_{1}+\alpha_{21} N_{2}}{K_{1}}\right)-c \frac{P N_{1}}{N_{1}+D_{1}+\beta N_{2}} \\
& \frac{d N_{2}}{d t}=r_{2} N_{2}\left(1-\frac{N_{2}+\alpha_{12} N_{1}}{K_{2}}\right)-c \frac{P \beta N_{2}}{N_{1}+D_{1}+\beta N_{2}}
\end{aligned}
$$

Hanski \& Korpimäki1995

Turchin \& Hanski1997
Gilg et al. 2003
Multiple predators (type III)

Seasonality (higher growth of

$N=$ lemmings in winter

Temporal resolution

No carrying capacity for $N$ responsible for a majority (approx. 50\%) of the mortality of these voles (Norrdahl \& Korpimäki 1995). First, a predator-prey model with seasonality was constructed. Values of model parameters were based primarily on the long-term field data collected by Korpimäki's group in western Finland. In the modified version of the model with seasonality, very complex population dynamics of voles were possible, and it was easy to pick up parameter values to generate stable dynamics, limit cycles and chaos. The critical question was what kind of vole dynamics are predicted by parameter values estimated from real data. If the model with field-estimated parameters generated population trajectories that are quantitatively similar to the observed dynamics, then the predation hypothesis explaining population cycles of voles was supported. Importantly, the model parameterized by field data really predicted vole dynamics that closely resembled the observed dynamics of boreal vole populations. Both the model-predicted and fieldobserved dynamics were chaotic, albeit with a statistically significant component. These results added a critical piece to the growing theoretical and observational body of evidence that 3-4year vole cycles in Fennoscandia and probably elsewhere in Eurasia are generated by delayed density dependence by specialist predators. In the early 1990s, no other hypothesis about the small mammal cycles had been formulated as a quantitative model and been successfully tested with field data.

This model led to more complex dynamics than the Lotka-Volterra or Leslie model, which were described based mostly on numerical analyses as chaotic, but with a periodic component. It is only recently that more analytical approaches 
have focused on how seasonality could affect predator-prey dynamics (Tyson \& Lutscher 2016), and they showed that seasonality could indeed be a major factor affecting dynamics. Such seasonal models are, however, mathematically much more difficult to understand in detail, which might explain why the very important contributions by Hanski may have not been applied to systems other than those for which they were developed. For the rodent-predator systems, however, Hanski's model formulations continue to inspire the development of new models (e.g., Taylor et al. 2013a, 2013b, Radchuk et al. 2016).

The seasonal model of Hanski et al. (1993) became the core of more complex models such as those of Hanski and Korpimäki (1995) and Turchin and Hanski (1997), which combined the ideas on generalist/specialist predation (Hanski et al. 1991) and seasonality (Fig. 1). Korpimäki's group had been collecting observational field data on population densities and diet composition of main avian and mammalian predators of small rodents in relation to the abundance indices of small mammals in western Finland. These data showed that the effect of predation by avian predators (three owl species and kestrels) was directly density-dependent without an obvious time lag (e.g. Korpimäki \& Norrdahl 1989a, 1991a, 1991b), whereas the effect of predation by small mustelids (least weasels and stoats) was density-dependent with a time lag of 6 to 12 months (Korpimäki et al. 1991).

This modelling work was further developed (Hanski \& Korpimäki 1995) by taking into account that there are three kinds of predators of small rodents. Specialist mammalian predators were thought to be instrumental in maintaining the fairly regular, multiannual oscillations (Henttonen et al. 1987, Korpimäki et al. 1991). Generalist predators have a stabilizing effect on dynamics of rodents (Erlinge et al. 1983), and nomadic avian predators similarly tend to stabilize prey dynamics (Korpimäki \& Norrdahl 1989b, 1991b) but additionally increase the regional synchrony of rodent populations (Ydenberg 1987, Korpimäki \& Norrdahl 1989a, Ims \& Steen 1990).

Most parameter combinations of the model of Hanski and Korpimäki (1995) generated high- amplitude, chaotic oscillations with a distinct periodic component. Indeed, the median parameter values predicted dynamics of voles resembling the observed 3-4-year vole oscillations in northern Fennoscandia. The results were not sensitive to a number of structural changes in the model, suggested by empirical results from the field. These structural changes included stochastic variation in the carrying capacity of prey (voles), prey refuge from predators at low density, intra-guild predation on mustelids by larger avian predators in the years when vole densities decline (Korpimäki \& Norrdahl 1989b), and assumption about winter breeding of Microtus voles. The model-predicted period and amplitude of oscillations agreed most closely with observations when the model included a low-density refuge for small mustelids. The results provided further support for the hypothesis that population fluctuations of voles were maintained by delayed density-dependence imposed by specialist predators, and also formed a basis for planning and executing large-scale field experiments on the factors driving high-amplitude multiannual population cycles in voles in northern Europe. These experiments further documented the roles of various types of predators (Korpimäki \& Norrdahl 1998, Klemola et al. 2000, Huitu et al. 2003 Korpimäki et al. 2002, 2004, 2005).

Turchin and Hanski (1997) analysed generalist/specialist predation hypothesis and constructed a model for vole population dynamics, and made predictions about the quantitative pattern of the latitudinal shift in vole dynamics. The model predicted well the latitudinal shift in the amplitude and periodicity of population fluctuations. The model also predicted that vole dynamics should shift from stable to chaotic with increasing latitude, a result also achieved from nonlinear time-series analysis of the data. The success of the model at predicting the shifts in amplitude and stability along the geographical gradient in Fennoscandia supports the roles of specialist and generalist predators in vole population dynamics.

Another noteworthy addition was a seasonal model with two competing rodent species subjected to predation by the least weasel, "apparent competition" (Hanski \& Henttonen 1996; see also Fig. 1). Numerical simulations of this 
model generated transient dynamics that alternated between long time periods with cyclic and non-cyclic fluctuations, resembling the observed changes in cyclicity in Lapland, and thus offered a simple explanation of the "loss of cyclicity" that started to be observed in northern Fennoscandia in the 1980s and the early 1990s (Henttonen 1987, Henttonen et al. 1987, Henttonen 2000, Henttonen \& Wallgren 2001, Lindström \& Hörnfeldt 1994, Hörnfeldt 2004, Ims et al. 2008, Henden et al. 2009, Cornulier et al. 2013). Hanski considered such transience due to "intrinsic system behaviour" to play out on relatively small spatial scales while the phenomenon of "lost" or "dampened cycles" has more recently been found to be large-scale (Cornulier et al.2013) and most often interpreted as a signal of environmental change.

Hanski and coworkers published some general reviews on the effects of predation and community composition on small mammals cycles in Fennoscandia (Henttonen \& Hanski 2000, Hanski \& Henttonen 2002, Hanski et al. 2001).

The final model in the succession of "Hanski models of predator-prey in seasonal environments" considered the high-arctic predator-prey community in Greenland. Collared lemmings (Dicrostonyx groenlandicus) and stoats (Mustela erminea) displayed similar (4-year period) but delayed (by one year) population dynamics in Greenland (Sittler 1995). Aided by exceptionally detailed season-specific data on the single rodent species in this ecosystem and all of its predators' functional and numerical responses, Gilg et al. (2003) built a model, starting from Hanski and Korpimäki (1995), that yielded unique insights into the dynamics of this specific predator-prey system and a more general lesson about the regulatory potential of complex predator guilds. Before Hanski's involvement, breeding densities and success had already been documented for most predators (arctic fox, snowy owl and longtailed skua) for over more than two cycle periods. However, there was almost no knowledge about the functional responses of predators. For the period 1998-2002, i.e. one lemming cycle, research effort was increased; e.g. lemmings were live-trapped in several plots throughout the summer snow-free season in order to "calibrate" the long-term relative abundance inferred from the census of winter nests, monitored by Sittler since 1988. Predators' functional responses were closely monitored by mixing an array of specific methods, from radio tracking to detailed diet analysis and behavioural observations made from hides (Gilg 2002, Gilg et al. 2006).

Adapting Hanski and Korpimäki model (1995) was challenging because there were four migratory or partly nomadic predators (instead of one resident in the Fennoscandian model) and a reverse seasonality had to be implemented, since collared lemmings mainly breed in winter. Each of the four predators has its own phenology and specific functional and numerical responses (the latest ones being even considered separately for the adults and the young) and this inflated the number of parameters used in the Greenland model (e.g. 17 additional parameters to account for the three so called "generalist" predators). Another major difference was that, although the so called "specialist" mustelid predator was dynamically linked with rodents in both models, a ratio-dependent growth rate and two distinct (according to season and rodent threshold density) fixed mortality rates were used in the Fennoscandia model while in Greenland, according to existing limited knowledge, only one constant annual breeding event could be assumed (regardless of the prey density) and two mortality rates depending on the current rodent density, but with no seasonality.

Also, in Greenland, a Type III functional response was used for all four predators, including the "specialized" stoat, assuming that even for the latter, at a very low prey density (which often occurs in 2 out of 4 years during the lemming cycle), some lemmings would find refuges and escape stoat predation, contrary to what is assumed by a Type II response where the percentage of the prey population killed every day increases exponentially as prey density declines. Finally, and this is probably what Hanski found the most interesting in the Greenland model, all kinds of carrying capacities, which had initially been implemented, were lifted in the Greenland model, both for prey and predators. This suggested that, although the main prey and predator species had exponential growth rates, the complex interplay between the five species was sufficient to "regulate" the population dynamics of 
the entire community and to keep the lemming cycles under control.

A few years later, this model was successfully used to answer more applied questions related to the dampening of the lemming cycles in Greenland (Gilg et al. 2009). Here again, seasonality (i.e., the changes in the "duration of the snow free period") appeared to be very important since it could explain most of the dynamic changes in lemmings and their predators observed in the field at two distinct sites.

\section{Legacy of Hanski models}

Hanski's work on shrews and small rodents (voles and lemmings) has profoundly advanced our understanding of their highly variable dynamics in time and space. Although he contributed significantly to analyses and syntheses of empirical data (in particular for shrews), it is Hanski's mathematical models of rodent population dynamics that has had the largest impact. Still, it is more than just the models, but more about a way to approach specific problems/systems and to use models to make these specific cases relevant for ecology in general.

The models developed by Hanski were strongly driven by (1) the empirical patterns known at that time, both in terms of population dynamics (e.g. geographical gradient in Fennoscandia) and plausible mechanisms (generalist/specialist predation, seasonality, difference between preys), and (2) his careful consideration of the available empirical evidence when assessing the shapes and parameters for the different functional and numerical responses. He was often very explicit about the lack of information regarding many of the predator-prey relationships, and his interest in the Greenland system was in large part driven by the possibility he saw for having a model firmly grounded in relationships estimated from field data. Many of the ideas developed through his targeted models will continue to have a great impact, both in terms of motivating empirical work for better estimation of relationships between predators and preys in different seasons, and as examples of mathematical models with varying degrees of complex dynamics.

\section{Acknowledgements}

We were privileged to know Ilkka Hanski, either for longer or a bit shorter periods (HH 44 years, OG 20 years, RAI 27 years, EK 30 years, NY 20 years) and to work with him. His determination in completing projects and manuscripts was phenomenal.

\section{References}

Andersson, M. \& Erlinge, S. 1977: Influence of predation on rodent populations. - Oikos 29: 591-597.

Cornulier, T., Yoccoz, N. G., Bretagnolle, V., Brommer, J. E., Butet, A., Ecke, F., Elston, D. E., Framstad, E., Henttonen, H., Hörnfeldt, B., Huitu, O., Imholt, C., Ims, R. A., Jacob, J., Jedrzejewska, B., Millon, A., Petty, S. J., Pietiäinen, H., Tkadlec, E., Zub, K. \& Lambin, X. 2013: Europe-wide dampening of population cycles in keystone herbivores. - Science 340: 63-66.

Dokuchaev, N. E. 1989: Population ecology of Sorex shrews in North-East Siberia. - Ann. Zool. Fennici 26: 371-379.

Erlinge, S., Göransson, G., Hansson, L., Högstedt, G., Liberg, O., Nilsson, I. N., Nilsson, T., von Schantz, T. \& Sylvén, M. 1983: Predation as a regulating factor in small rodent populations in southern Sweden. - Oikos 40: $36-52$.

Gilg, O. 2002: The summer decline of the collared lemming (Dicrostonyx groenlandicus) in high arctic Greenland. - Oikos 99: 499-510.

Gilg, O., Hanski, I. \& Sittler, B. 2003: Cyclic dynamics in a simple vertebrate predator-prey community. - Science 302: 866-868.

Gilg, O., Sittler, B. \& Hanski, I. 2009: Climate change and cyclic predator-prey population dynamics in the highArctic. - Global Change Biology 15: 2634-2652.

Gilg, O., Sittler, B., Sabard, B., Hurstel, A., Sané, R., Delattre, P. \& Hanski, I. 2006: Functional and numerical responses of four lemming predators in high arctic Greenland. - Oikos 113: 196-213.

Hanski, I. 1987a: Pine sawfly population dynamics: patterns, processes, problems. - Oikos 50: 327-335.

Hanski, I. 1987b: Populations of small mammals cycle unless they don't. - Trends Ecol. Evol. 2: 55-56.

Hanski, I. 1989: Population biology of Eurasian shrews: Towards a synthesis. - Ann. Zool. Fennici 26: 469-479.

Hanski, I. 1994: Population biological consequences of body size in shrews. - In: Merritt, J. F., Kirkland, G. L. Jr. \& Rose, R. K. (eds.), Advances in the biology of shrews: 15-26. Spec. Publ. 18, Carnegie Museum of Natural History.

Hanski, I. \& Henttonen, H. 1996: Predation on competing rodent species: a simple explanation of complex patterns. - J.Anim. Ecol. 65: 220-232.

Hanski, I. \& Henttonen, H. 2002: Population cycles of small rodents in Fennoscandia. - In: Berryman, A. (ed.), Populations cycles: the case for trophic interactions: 44-68. Oxford University Press, New York. 
Hanski, I. \& Korpimäki, E. 1995: Microtine rodent dynamics in northern Europe: parameterized models for the predator-prey interaction. - Ecology 76: 840-850.

Hanski, I. \& Pankakoski, E. (eds.) 1989: Population biology of Eurasian shrews: Symposium held at Lammi, Finland, on 3 to 5 March 1989. - Ann. Zool. Fennici 26: 331-479.

Hanski, I. \& Parviainen, P. 1987: Cocoon predation by small mammals, and pine sawfly population dynamics. Oikos 45: 125-136.

Hanski, I., Hansson, L. \& Henttonen, H. 1991: Specialist predators, generalist predators, and the microtine rodent cycle. - J. Anim. Ecol. 69: 353-367.

Hanski, I., Turchin, P., Korpimäki, E. \& Henttonen, H. 1993: Population oscillations of boreal rodents: regulation by mustelid predators leads to chaos. - Nature 364 : 232-235.

Hanski, I., Henttonen, H., Korpimäki, E., Oksanen, L. \& Turchin, P. 2001: Small rodent dynamics and predation. - Ecology 82: 1505-1520.

Hansson, L. \& Henttonen, H. 1985a: Gradients in cyclicity of small rodents: importance of latitude and snow cover. Oecologia 67: 394-402.

Hansson, L. \& Henttonen, H. 1985b: Regional differences in cyclicity and reproduction in Clethrionomys spp.: are they related? - Ann. Zool. Fennici 22: 277-288.

Hansson, L. \& Henttonen, H. 1988: Rodent dynamics as community processes. - Trends Ecol. Evol. 3: 195-200.

Henden, J.-A., Ims, R. A. \& Yoccoz, N. G. 2009: Nonstationary spatio-temporal small rodent dynamics: evidence from long-term Norwegian fox bounty data. - J. Anim. Ecol. 78: 636-645.

Henttonen, H. 1987: The impact of spacing behavior in microtine rodents on the dynamics of least weasels Mustela nivalis. - Oikos 50: 366-370.

Henttonen, H. 2000: Long-term dynamics of the bank vole Clethrionomys glareolus at Pallasjärvi, northern Finnish taiga. - Polish J. Ecol. 48 (Suppl.): 87-96.

Henttonen, H. \& Hanski, I. 2000: Population dynamics of small rodents in northern Fennoscandia. - In: Perry, J. N., Smith, R. H., Woiwod, I. P. \& Morse, D. (eds), Chaos in real data. The analysis of non-linear dynamics from short ecological time series: 73-96. Kluwer Academic Publishers, Dordrecht.

Henttonen, H. \& Wallgren, H. 2001: Small rodent dynamics and communities in the birch forest zone of northern Fennoscandia. - In: Wielgolaski, F. E. (ed.), Nordic mountain birch forest ecosystem: 261-278. Man and the Biosphere Series vol. 27, UNESCO, Paris and Parthenon Publishing Group, New York and London.

Henttonen, H., McGuire, A. D. \& Hansson, L. 1985: Comparisons of amplitudes and frequencies (spectral analyses) of density variations in long-term data sets of Clethrionomys species. - Ann. Zool. Fennici 22: 221-228.

Henttonen, H., Oksanen, T., Jortikka, A. \& Haukisalmi, V. 1987: How much do weasels shape microtine cycles in the northern Fennoscandian taiga? - Oikos 50: 353-365.

Henttonen, H., Haukisalmi, V., Kaikusalo, A., Korpimäki, E., Norrdahl, K. \& Skarén, U. A. P. 1989: Long-term popu- lation dynamics of the common shrew Sorex araneus in Finland. - Ann. Zool. Fennici 26: 349-355.

Huitu, O., Koivula, M., Korpimäki, E., Klemola, T. \& Norrdahl, K. 2003: Winter food supply limits growth of northern vole populations in the absence of predation. Ecology 84: 2108-2118.

Hörnfeldt, B. 2004: Long-term decline in numbers of cyclic voles in boreal Sweden: analysis and presentation of hypotheses. - Oikos 107: 376-392.

Ims, R. A. \& Steen, H. 1990: Regional synchrony of cyclic microtine populations: a theoretical evaluation of the role of nomadic predators. - Oikos 57: 381-387.

Ims, R. A., Henden, J.-A. \& Killengreen, S. T. 2008: Collapsing population cycles. - Trends Ecol. Evol. 23: 79-86.

Kaikusalo, A. \& Hanski, I. 1985: Population dynamics of Sorex araneus and S. caecutiens in Finnish Lapland. Acta Zool. Fennica 173: 283-285.

Klemola, T., Koivula, M., Korpimäki, E. \& Norrdahl, K. 2000: Experimental tests of predation and food hypotheses for population cycles of voles. - Proc. R. Soc. London B 267: 351-356.

Korpimäki, E. \& Norrdahl, K. 1989a: Predation of Tengmalm's owls: numerical responses, functional responses and dampening impact on population fluctuations of microtines. - Oikos 54: 154-164.

Korpimäki, E. \& Norrdahl, K. 1989b: Avian predation on mustelids in Europe 1: occurrence and effects on body size variation and life traits. - Oikos 55: 205-215.

Korpimäki, E. \& Norrdahl, K. 1991a: Numerical and functional responses of kestrels, short-eared owls, and longeared owls to vole densities. - Ecology 72: 814-826.

Korpimäki, E. \& Norrdahl, K. 1991b: Do breeding nomadic avian predators dampen population fluctuations of small mammals? - Oikos 62: 195-208.

Korpimäki, E. \& Norrdahl, K. 1998: Experimental reduction of predators reverses the crash phase of small-rodent cycles. - Ecology 79: 2448-2455.

Korpimäki, E., Norrdahl, K. \& Rinta-Jaskari, T. 1991: Responses of stoats and least weasels to fluctuating vole abundances: is the low phase of the vole cycle due to mustelid predation? - Oecologia 88: 552-561.

Korpimäki, E., Brown, P. R., Jacob, J. \& Pech, R. P. 2004: The puzzles of population cycles and outbreaks of small mammals solved? - BioScience 54: 1071-1079.

Korpimäki, E., Norrdahl, K., Huitu, O. \& Klemola, T. 2005: Predator-induced synchrony in population oscillations of co-existing small mammal species. - Proc. R. Soc. London B 272: 193-202.

Korpimäki, E., Norrdahl, K., Klemola, T., Pettersen, T. \& Stenseth, N. C. 2002: Dynamic effects of predators on cyclic voles: field experimentation and model extrapolation. - Proc. R. Soc. London B 269: 991-997.

Lack, D. 1954: The natural regulation of animal numbers. Oxford University Press, Oxford.

Leslie, P. H. 1948: Some further notes on the use of matrices in population mathematics. - Biometrika 35: 213-245.

Lindström, E. R. \& Hörnfeldt, B. 1994: Vole cycles, snow depth and fox predation. - Oikos 70: 156-160.

Lotka, A. J. 1925: Elements of physical biology. - Williams \& Wilkins, Baltimore. 
May, R. M. 1972: Limit cycles in predator-prey communities. - Science 177: 900-902.

May, R. M. 1973: Complexity and stability in model ecosystems. - Princeton University Press, Princeton, USA.

Moraleva, N. V. 1989: Intraspecific interactions in the common shrew Sorex araneus in central Siberia. - Ann. Zool. Fennici 26: 425-432.

Norrdahl, K. \& Korpimäki, E. 1995: Mortality factors in a cyclic vole population. - Proc. R. Soc. London B 261: 49-53.

Radchuk, V., Ims, R. A. \& Andreassen, H. P. 2016: From individuals to population cycles: the role of extrinsic and intrinsic factors in rodent populations. - Ecology 97: 720-732.

Rosenzweig, M. L. \& MacArthur, R. H. 1963: Graphical representation and stability conditions of predator-prey interactions. - Am. Nat. 97: 209-223.

Sheftel, B. I. 1989: Long-term and seasonal dynamics of shrews in central Siberia. - Ann. Zool. Fennici 26: 357-369.

Sittler, B. 1995: Response of stoat (Mustela erminea) to a fluctuating lemming (Dicrostonyx groenlandicus) popu- lation in North East Greenland: preliminary results from a long-term study. - Ann. Zool. Fennici 32: 79-92.

Taylor, R. A., Sherratt, J. A. \& White, A. 2013a: Seasonal forcing and multi-year cycles in interacting populations: lessons from a predator-prey model. - J. Math. Biology 67: 1741-1764.

Taylor, R. A., White, A. \& Sherratt, J. A. 2013b: How do variations in seasonality affect population cycles? Proc. R. Soc. London B 280: 20122714, doi: 10.1098/ rspb.2012.2714.

Turchin, P. \& Hanski, I. 1997: An empirically based model for latitudinal gradient in vole population dynamics. Am. Nat. 149: 842-874.

Tyson, R. \& Lutscher, F. 2016: Seasonally varying predation behavior and climate shifts are predicted to affect predator-prey cycles. - Am. Nat. 188: 539-553

Volterra, V. 1926: Variazioni e fluttuazioni del numero d'individui in specie animali conviventi. - Mem. Acad. Lincei Roma 2: 31-113.

Ydenberg, R. C. 1987: Nomadic predators and geographical synchrony in microtine population cycles. - Oikos 50: 270-272. 